\title{
O WhatsApp como extensão da sala de aula: 0 ensino de História na palma da mão ${ }^{1}$
}

\author{
WhatsApp as an extension of the classroom: \\ History teaching in the palm of hand
}

Cristiano Gomes Lopes*

Braz Batista Vas ${ }^{\star *}$

\section{RESUMo}

O século XXI nos apresenta constantes avanços no campo das Tecnologias Digitais da Informação e Comunicação (TDIC), com desdobramentos em todas as esferas da vida humana, inclusive no âmbito educacional. Este trabalho é fruto de estudo realizado no curso de Mestrado Profissional em Ensino de História (PROFHISTÓRIA) que destacou a importância dos usos das TDIC como ferramentas de ensino da disciplina História, enfatizando especificamente o uso pedagógico dos grupos formados dentro da plataforma do aplicativo WhatsApp, buscando fazer desse ambiente virtual uma extensão da sala de aula. Para tanto, foi necessária a verificação das potencialidades didáticas do aplicativo na promoção de ensino e aprendizagem de forma colaborativa, em uma turma do ensino médio. Constataram-se as condições de funcionamento efetivo desses grupos, como extensão da sala de aula.

Palavras-chave: WhatsApp; aprendizagem móvel; aprendizagem histórica e colaborativa.

\section{Abstract}

The $21^{\text {st }}$ century brings us constant advances in the field of Digital Technologies of Information and Communication (DTIC), with consequences in all spheres of human life, including in Education. This work is the result of a study developed during my Professional Master's course in History Teaching (PROFHISTÓRIA), that focused the importance of the DTIC uses as teaching tools in History, specifically emphasizing the pedagogical use of the groups formed within the WhatsApp application platform, aiming to make this virtual environment an extension of the classroom. Therefore, it was necessary to verify the application of the educational potential in promoting teaching and learning historical collaboratively in a high school class. We observed the operating conditions of these groups, as an extension of the classroom.

Keywords: WhatsApp; mobile learning; historical and collaborative learning.

\footnotetext{
* Mestre em Ensino de História, Universidade Federal do Tocantins (UFT). Araguaína, TO, Brasil. cgomeslopes@bol.com.br

** Doutor em História pela Universidade Estadual Paulista Júlio de Mesquita Filho (Unesp/Franca). Universidade Federal do Tocantins (UFT). Araguaína, TO, Brasil. brazbv@gmail.com
} 
O século XXI destaca-se pelo crescente número de avanços no campo das Tecnologias Digitais da Informação e Comunicação (TDIC) com desdobramentos em todas as esferas da vida humana, inclusive no âmbito educacional, na medida em que a informação, após sua seleção, interpretação e entendimento, tende a se transformar em conhecimento.

O uso massivo de redes sociais e de aplicativos móveis modela essa sociedade do conhecimento, com reflexos no ambiente escolar (Fleury, 2003), e isso causa uma densa discussão entre gestores, docentes, discentes e pais. Com base nessa discussão, uns tacham as redes sociais como vilãs; outros enxergam toda a gama de possibilidades de utilização dessas redes como ferramentas de ensino e como ambientes propícios para a construção de conhecimento embasado na ubiquidade, colaboração e mobilidade.

Em 2009, em cenário de ascensão exponencial da telefonia móvel, nasceu o aplicativo de envio de mensagens instantâneas mais utilizado no mundo nos últimos tempos, o WhatsApp Messenger. Criado pelo norte-americano Brian Acton e pelo ucraniano Jan Koum, o WhatsApp rapidamente caiu no gosto popular, despertando o interesse de seus concorrentes e de investidores, tanto que a ferramenta foi vendida para o Facebook por cerca de 21 bilhões de dólares em fevereiro de 2014. Desde então, seu executivo chefe, Jan Koum, vem realizando várias alterações e atualizações no aplicativo, levando-o a conquistar mais e mais adeptos a cada dia.

Considerando-se o fato de que no início de 2016 o número de usuários do WhatsApp no mundo atingiu a marca de 1 bilhão de pessoas, podemos considerá-lo, com todas as suas funcionalidades, como uma ferramenta pedagógica em potencial, se for utilizado de forma intencional, buscando torná-lo uma espécie de ambiente virtual de aprendizagem, que deve ser tutorado e administrado pelos professores, fazendo desse ambiente uma extensão da sala de aula.

Usar pedagogicamente as redes sociais on-line e os aplicativos para dispositivos móveis requer certo cuidado, como propõe Margarita Gomez (2010):

O mundo das redes sociais é relativamente novo. Os programas de redes sociais, sejam pessoais, temáticas ou profissionais, na realidade não foram criados para atividades educativas, embora nas escolas se estejam usando alguns deles ... A rede é mais um espaço da escola contemporânea que necessita orientação e cuidado para se transformar em um dispositivo pedagógico. (Gomez, 2010, p.88-99) 
Muitos são os cuidados a serem tomados antes de se fazer o uso pedagógico das TDIC, em especial as redes sociais on-line. Não se pode pensar que esses recursos sejam a salvação para todas as mazelas que assolam a educação, pois muitos consideram que incorporar as TDIC no contexto escolar, mesmo sem a devida formação e competências para o manuseio consciente dessas ferramentas, consistiria em revolucionar a forma de se ensinar e aprender.

Não se pode pensar também que essas novas tecnologias irão substituir os professores, pelo contrário, "o protagonista das novas habilidades do século XXI não é propriamente o avanço tecnológico, por mais que isto seja decisivo, é o professor. A melhor tecnologia na escola ainda é o professor" (Demo, 2008, p.13).

Diante desse cenário, a escola e o professor podem e devem tirar partido do interesse e uso escancarado das redes sociais pela maioria dos alunos, até mesmo pelos professores, como mostra a pesquisa realizada pelo Centro de Estudos sobre as Tecnologias da Informação e da Comunicação (CETIC.br) em 2011, apontando a disponibilidade e o uso da internet no Brasil entre alunos e professores. Ao todo foram entrevistados 1.822 professores, dos quais $89 \%$ afirmaram ter acesso à internet em seus domicílios; $82 \%$ acessam a internet todos ou quase todos os dias, e $85 \%$ a acessam pelo celular. Cerca de $46 \%$ dos entrevistados responderam que fazem parte de grupos de discussão de professores na internet, e $60 \%$ afirmam não ter problemas em participar de redes sociais ou sites de relacionamento.

Para que não se faça confusão entre os termos "rede social" e "mídia social", é preciso deixar bem claro suas diferenças, pois muitos pensam tratar-se da mesma coisa. Podemos afirmar que "rede social" seja o relacionamento entre pessoas que compartilham objetivos e valores em comum. Portanto, não é necessário estar conectado à internet para fazer parte de uma rede social.

Raquel Recuero afirma que

Rede social é gente, é interação, é troca social. É um grupo de pessoas, compreendido através de uma metáfora de estrutura, a estrutura de rede. Os nós da rede representam cada indivíduo; suas conexões são os laços sociais que compõem os grupos. Esses laços são ampliados, complexificados e modificados a cada nova pessoa que conhecemos e com quem interagimos. (Recuero, 2009, p.29) 
Quando o termo é aplicado no universo on-line, surge o que conhecemos como "sites de rede social" (SRS) ou outro termo quase em desuso, "sites de relacionamento". Nesse caso, são sites utilizados para conectar pessoas, grupos ou instituições que desfrutam de interesses comuns por meio de um perfil com a finalidade de produzir e compartilhar vários conteúdos na internet. Nesse sentido, a interação é o ponto chave.

Já as mídias sociais são ambientes on-line que graças à estrutura da Web 2.0, possibilitam a criação, troca e compartilhamento de conteúdo em vários formatos, focando na divulgação desses conteúdos sem se preocupar com a interação das pessoas. Eder Lorenzo salienta que "mídia social é o termo usado para definir a interação interpessoal no meio eletrônico, e trata-se da produção de conteúdo de muitos para muitos. É importante deixar claro que as redes sociais on-line são apenas parte das mídias sociais" (Lorenzo, 2013, p.21).

O WhatsApp em si não é uma rede social, pois sua estrutura é compatível com a definição de mídia social, porém esse aplicativo tem a capacidade de gerar incontáveis redes sociais on-line pela formação de grupos em sua plataforma, fomentando de forma intensa a interação dos participantes, ou seja, dos “atores sociais" envolvidos.

É justamente por essa capacidade de gerar redes sociais on-line que o aplicativo pode ser utilizado como ambiente de aprendizagem, especialmente fora da sala de aula e complementar a ela, uma vez que torna possível proporcionar aos alunos alternativas que estimulem sua formação e constante aprendizado, através da aprendizagem móvel (mobile learning ou m-learning) ubíqua e colaborativa, ressaltando que essas práticas estão cada vez mais em voga no contexto educacional e profissional vigente, trazendo "consequências importantes, e representando significativos desafios para o processo de ensinar e de aprender, tanto nos contextos formais quanto nos contextos não formais de educação" (Saccol; Schlemmer; Barbosa, 2011, p.1).

O objetivo deste trabalho é estimular a aprendizagem ubíqua, móvel e colaborativa pelo uso pedagógico do aplicativo WhatsApp no ensino de História, fazendo desse recurso uma extensão da sala de aula. Para tanto, realizou-se pesquisa-ação (Thiollent, 2011) em uma unidade escolar por meio da qual buscamos: 
1) Verificar a importância do uso dos grupos do WhatsApp como ferramenta e ambiente que promove o ensino e a aprendizagem histórica de forma colaborativa;

2) Analisar os limites e possibilidades da aprendizagem que envolva a ubiquidade, a mobilidade e a colaboração;

3) Buscar canalizar o notório e explícito interesse dos alunos por esse aplicativo, utilizando-o pedagogicamente no ensino de História.

Como hipótese, afirmamos que o uso, com intencionalidade pedagógica, do WhatsApp, serve como ambiente de ensino e aprendizagem histórica, tornando a plataforma virtual desse aplicativo uma extensão da sala de aula e potencializando o ensino de História, embasado na aprendizagem ubíqua, móvel e colaborativa.

A fundamentação teórica está representada, de forma sucinta, no Quadro 1.

A seguir indicaremos elementos que sustentam a possibilidade de se trabalhar o ensino e a aprendizagem com mobilidade, ubiquidade e colaboração, meios efetivos de fazer dos grupos do WhatsApp extensão da sala de aula, desde que esses grupos sejam utilizados com intencionalidade pedagógica. Depois, apresentaremos como pano de fundo a caracterização da pesquisa-ação realizada, assim como a análise dos dados e resultados.

\section{AprendizAgem MÓVel, ubíQUA E COLABORATIVA}

Mobilidade, ubiquidade e colaboração são elementos intrínsecos e complementares no universo do ciberespaço. Tais conceitos carregam de sentido a velocidade estonteante da informação e o grau acelerado de interações que tecem as incontáveis teias da "grande rede". A sensação de estar em todo lugar ao mesmo tempo, como algo onipresente, leva as TDIC a conquistarem adeptos e mais adeptos. Pierre Lévy (1999, p.49-50) caracteriza esse cenário ressaltando a "ubiquidade da informação, documentos interativos interconectados, telecomunicação recíproca e assíncrona em grupos e entre grupos”.

A forma de se comunicar e de interagir ganhou dimensões jamais vistas em outros períodos históricos. O século XXI vem sendo marcado pela massificação do uso de redes sociais e de inúmeros aplicativos que aumentam exponencialmente o fluxo de produção e circulação de informações, afetando a 
Quadro 1 - Fundamentação teórica

\begin{tabular}{|c|c|c|}
\hline Abordagem & Autor & Contribuição \\
\hline $\begin{array}{l}\text { Tecnologias Digitais da } \\
\text { Comunicação e } \\
\text { Informação (TDIC) }\end{array}$ & $\begin{array}{l}\text { Pierre Lévy } \\
\text { (1999) }\end{array}$ & $\begin{array}{l}\text { - Tecnologias da inteligência; } \\
\text { - Inteligência Coletiva. }\end{array}$ \\
\hline Redes Sociais On-line & $\begin{array}{l}\text { Raquel Ricuero } \\
\text { (2009) }\end{array}$ & $\begin{array}{l}\text { - Conceituação de Redes Sociais On-line, } \\
\text { Mídias Sociais; } \\
\text { - Redes Sociais On-line no contexto } \\
\text { educacional. }\end{array}$ \\
\hline $\begin{array}{l}\text { Uso das TDIC no } \\
\text { contexto educacional }\end{array}$ & $\begin{array}{l}\text { Vani Moreira } \\
\text { Kenski (2003) }\end{array}$ & $\begin{array}{l}\text { - Discute as mudanças ocorridas no espaço } \\
\text { educacional em virtude da revolução digital } \\
\text { e seus impactos no universo escolar e } \\
\text { consequentemente no modo de se ensinar e } \\
\text { de se aprender na era digital. }\end{array}$ \\
\hline Ensino de História & $\begin{array}{l}\text { Selva Guimarães } \\
\text { Fonseca (2009) } \\
\text { Marieta Ferreira e } \\
\text { Renato Franco } \\
\text { (2013) }\end{array}$ & $\begin{array}{l}\text { - A internet constitui, na atualidade, } \\
\text { importante meio de comunicação, fonte } \\
\text { de informações, dados, textos, mapas, } \\
\text { documentos, leis, fotografias, pinturas, } \\
\text { canções, poemas, enfim, uma } \\
\text { multiplicidade de registros da experiência } \\
\text { histórica das diferentes sociedades do } \\
\text { planeta; } \\
\text { - A História e os historiadores não devem } \\
\text { ficar de fora do processo de informatização } \\
\text { das últimas décadas; } \\
\text { - As tecnologias digitais possuem } \\
\text { características relacionadas a onipresença } \\
\text { ou ubiquidade. }\end{array}$ \\
\hline $\begin{array}{l}\text { Ensino de História por } \\
\text { meio das TDIC }\end{array}$ & $\begin{array}{l}\text { Isabel Barca } \\
\text { (2007) }\end{array}$ & $\begin{array}{l}\text { - O ensino de História concebe trabalhar com } \\
\text { a diversidade de fontes históricas contidas } \\
\text { no universo da grande rede, vislumbra a } \\
\text { possibilidade de os alunos reunirem } \\
\text { condições de ler, interpretar fontes, } \\
\text { discorrer sobre pontos de vista que os } \\
\text { levem a pensar historicamente com a } \\
\text { intermediação e orientação do professor. }\end{array}$ \\
\hline Método da Pesquisa-ação & $\begin{array}{l}\text { Michel Thiollent } \\
\text { (2011) }\end{array}$ & $\begin{array}{l}\text { - A pesquisa-ação pode ser concebida como } \\
\text { método, um caminho ou um conjunto de } \\
\text { procedimentos para interligar } \\
\text { conhecimento e ação, ou extrair da ação } \\
\text { novos conhecimentos. }\end{array}$ \\
\hline
\end{tabular}

Fonte: Estruturado pelo autor 
forma como as pessoas aprendem, assimilam e constroem conhecimentos. Dessa forma, aprender em qualquer lugar, a todo momento e de forma colaborativa, são exemplos marcantes dos processos de aprendizagem que norteiam a "era digital", pois:

Aprender em processos de mobilidade e ubiquidade implica abrir-se às potencialidades que essas tecnologias oferecem. "Envolve aguçar o senso de observação do entorno para perceber tais possibilidades, ser autônomo e autor do seu processo de aprender." (Saccol; Schlemmer; Barbosa, 2011, p.6)

Esses aspectos da contemporaneidade também perpassam pela construção do currículo escolar, uma vez que esse instrumento deve ultrapassar o mecanicismo estanque e linear que engessa o potencial de construção social desse espaço de saber/poder, o qual produz identidades particulares e coletivas, dando forma, sentidos e significado às singularidades culturais (Weber; Santos; Santos, 2012).

Nessa perspectiva, o web-currículo visa incorporar de forma efetiva, intencional e pedagógica, as principais características do universo digital no desenvolvimento do currículo, apropriando-se do potencial didático, interativo e colaborativo das TDIC e estimulando o protagonismo dos alunos no processo de construção de conhecimento.

Assim, a aprendizagem em ambientes não convencionais - como os virtuais - aponta para as propostas do "ensino híbrido", que vem tomando forma e espaço no universo educacional por meio de aspectos que englobam a educação formal e a não formal, estabelecendo laços de integração nessas duas maneiras de instruir-se. Mesclar elementos da educação presencial com elementos da educação a distância proporcionará ganhos no processo de ensino-aprendizagem, pois não aprendemos só no limitado espaço da sala de aula, aprendemos e ensinamos em muitos outros espaços e lugares, tudo isso graças às mídias digitais que canalizam, armazenam e distribuem o saber produzido individual e coletivamente. Moran defende essa forma de ensinar afirmando que:

O ensino é híbrido, também, porque não se reduz ao que planejamos institucional e intencionalmente. Aprendemos por meio de processos organizados, junto com processos abertos, informais. Aprendemos quando estamos com um professor e aprendemos sozinhos, com colegas, com desconhecidos. Aprendemos de 
modo intencional e de modo espontâneo, quando estudamos e também quando nos divertimos ... todos somos aprendizes e mestres, consumidores e produtores de informação. (Moran, 2015, p.28)

Somos capazes de aprender por várias formas e maneiras, por isso o "ensino híbrido" vem com a proposta de se buscarem as melhores combinações dessas formas de aprendizagem e potencializá-las. Assim poderemos aprender mais e melhor, alternando a organização do trabalho docente em momentos presenciais na sala de aula física e outros momentos em ambientes mediados pela internet/web, por mídias digitais que promovam não apenas o estudo individual, mas também o aprendizado coletivo mediante interação, compartilhamento e colaboração fomentados pelas redes sociais.

\section{O WhatsApp COMO EXTENSÃO DA SALA \\ DE AULA: TESTANDO NOVAS POSSIBILIDADES}

A propósito de testar as possibilidades das TDIC, realizamos a pesquisa-ação na turma do $3^{\circ}$ ano do ensino médio, investigando se os grupos do WhatsApp podem ser utilizados como extensão da sala de aula da disciplina História, na medida em que esses grupos são planejados didática e pedagogicamente com a finalidade de serem ambientes propícios à construção de conhecimento histórico, apoiados pelo viés da colaboração, mobilidade e ubiquidade, potencialidades características das TDIC - no caso específico desta pesquisa, os grupos do WhatsApp.

A pesquisa-ação foi realizada na Escola Estadual de Ensino Médio Professora Elza Maria Correa Dantas, no município de São Domingos do Araguaia, sudeste do estado do Pará, fundada em março de 1991. É a única unidade escolar que oferece o ensino médio na cidade, atendendo a uma demanda urbana e rural de 1.356 alunos matriculados em 2015.

Para tanto, faz-se necessário verificar a importância do uso dos grupos do WhatsApp como ferramenta e ambiente que promovem o ensino e a aprendizagem histórica de forma colaborativa. Também é preciso analisar as limitações e as possibilidades dessa aprendizagem dentro desses ambientes, canalizando o interesse de alunos e professores pelo aplicativo. 
A pesquisa foi iniciada em agosto de 2015 e estendeu-se até fevereiro de 2016. No primeiro contato os alunos conheceram os objetivos da pesquisa e a sua pretensão de investigar e constatar se de fato o uso pedagógico dos grupos do WhatsApp poderiam ou não ser utilizados como extensão da sala de aula no estudo da disciplina História, elencando a sua importância para o contexto da educação que contemple o uso das TDIC no universo escolar. Antes de efetivamente formar os grupos com a turma escolhida, houve um segundo encontro com os alunos para que coletivamente se elaborasse um conjunto de normas e critérios de uso e participação nos grupos que seriam pesquisados-utilizados. Todos se comprometeram a seguir as determinações criadas conjuntamente, pois tais regras não teriam caráter de imposição, uma vez que os próprios alunos participaram de sua construção.

Depois da criação e aprovação das regras de participação nos grupos, processo esse que durou de agosto a setembro de 2015, foram colhidos os números telefônicos dos alunos e do professor, e finalmente criaram-se os grupos em outubro de 2015, iniciando de fato a pesquisa de campo com a análise dos grupos do WhatsApp.

Foram criados cinco grupos ao todo, cada um com uma função, como podemos observar no Quadro 2.

Quadro 2 - Grupos do WhatsApp e suas funções

\begin{tabular}{|c|c|c|c|}
\hline Grupo & Tema & Função / Funcionamento & Duração \\
\hline 1 & $\begin{array}{l}\text { Curtindo a } \\
\text { História }\end{array}$ & $\begin{array}{l}\text { Trabalhar os conteúdos da disciplina História } \\
\text { abordados em sala de aula. } \\
\text { Possibilitar a troca de informações, discussões, } \\
\text { compartilhamento e produção de textos, vídeos, fotos, } \\
\text { links, áudios e demais materiais que possam servir de } \\
\text { apoio ao estudo e à construção de conhecimento } \\
\text { histórico dos conteúdos trabalhados em sala de aula. } \\
\text { Intermediação do professor e do pesquisador, ambos } \\
\text { administradores do grupo. } \\
\text { O grupo terá suas atividades paralisadas na semana que } \\
\text { anteceder o período de provas, voltando a ser ativado no } \\
\text { término da semana de avaliações da escola. }\end{array}$ & $\begin{array}{c}1^{\text {a }} \text { fase: } \\
5 \text { out. } \\
2015 \\
\text { a } \\
6 \text { nov. } \\
2015 \\
2^{\text {a fase: }} \\
16 \text { nov. } \\
2015 \\
\text { a } \\
10 \text { jan. } \\
2016\end{array}$ \\
\hline
\end{tabular}


continuação

\begin{tabular}{|c|c|c|c|}
\hline 2 & Tira dúvidas & $\begin{array}{l}\text { Espaço para que o professor e os alunos possam } \\
\text { esclarecer dúvidas; } \\
\text { Possibilitar aos alunos que têm mais entendimento dos } \\
\text { conteúdos históricos a colaboração efetiva na } \\
\text { aprendizagem dos demais membros do grupo. } \\
\text { O grupo tem horário definido para o envio das dúvidas } \\
\text { aos mediadores, e prazo estipulado para o feedback das } \\
\text { respostas e intervenções. } \\
\text { Os administradores do grupo foram os dois alunos mais } \\
\text { atuantes do primeiro grupo, mais o professor da turma } \\
\text { e o pesquisador. } \\
\text { Esse grupo foi ativado na semana que antecedeu o } \\
\text { período de provas da escola, permanecendo ativo até o } \\
\text { dia da prova de História, retornando à ativa novamente } \\
\text { na semana que antecedeu o próximo período de provas. }\end{array}$ & $\begin{array}{c}1^{\text {a fase: }} \\
6 \text { nov. } \\
2015 \\
\text { a } \\
16 \text { nov. } \\
2015 \\
2^{\text {a fase: }} \\
10 \text { jan. } \\
2016 \\
\text { a } \\
17 \text { jan. } \\
2016\end{array}$ \\
\hline 3 & $\begin{array}{l}\text { Exercitando } \\
\text { a História }\end{array}$ & $\begin{array}{l}\text { Espaço para a resolução de atividades, trabalhos e } \\
\text { exercícios propostos pelos mediadores do grupo. } \\
\text { O professor da turma e o pesquisador são os mediadores } \\
\text { do grupo. } \\
\text { O grupo ficou ativo durante todo o período da pesquisa. }\end{array}$ & $\begin{array}{c}5 \text { out. } \\
2015 \\
\text { a } \\
5 \text { fev. } 2016\end{array}$ \\
\hline 4 & $\begin{array}{l}\text { História } \\
\text { in off }\end{array}$ & $\begin{array}{l}\text { Este grupo tem apenas fins lúdicos, de diversão, e usa a } \\
\text { informalidade dos alunos com o objetivo de dar vazão } \\
\text { às postagens que não contribuem objetivamente na } \\
\text { formação e aprendizado dos participantes, para que } \\
\text { postagens indesejadas não sejam compartilhadas nos } \\
\text { outros grupos. }\end{array}$ & $\begin{array}{c}5 \text { out. } \\
2015 \\
\text { a } \\
5 \text { fev. } 2016\end{array}$ \\
\hline 5 & Avaliação & $\begin{array}{l}\text { Fase final da aplicação da pesquisa-ação. } \\
\text { Discussão dos resultados obtidos, da participação dos } \\
\text { alunos e dos mediadores. } \\
\text { Verificação dos limites e possibilidades do uso dos } \\
\text { grupos como extensão da sala de aula. } \\
\text { Formado pelos dois alunos que mais tenham } \\
\text { participado nos três primeiros grupos, pelos dois alunos } \\
\text { com menor participação naqueles, mais o professor e o } \\
\text { pesquisador. }\end{array}$ & $\begin{array}{c}25 \text { jan. } \\
2016 \\
\text { a } \\
5 \text { fev. } 2016\end{array}$ \\
\hline
\end{tabular}

Fonte: Dados da pesquisa.

\section{CARACTERIZAÇÃo DA PESQUISA}

Os sujeitos da pesquisa foram 40 alunos do $3^{\circ}$ ano, turma " $A$ " do turno matutino, e seu professor da disciplina de História, tendo como objeto de estudos a formação, participação, colaboração e construção do conhecimento 
histórico dentro de grupos do aplicativo WhatsApp formados pela turma escolhida para a aplicação da pesquisa, assim como a mediação dos docentes envolvidos. Por ser uma pesquisa-ação (Thiollent, 2011), o pesquisador também se inclui como um dos sujeitos da pesquisa.

Observou-se a participação dos discentes no tocante às discussões levantadas pelos mediadores (professor e pesquisador) e analisou-se a interação e a colaboração dos alunos na construção de conhecimentos e competências de saberes históricos trabalhados nas aulas presenciais e continuadas no ambiente virtual da plataforma dos grupos criados no WhatsApp. A observação se deu durante o período correspondente a um semestre letivo, levando também em consideração a mediação dos professores de História envolvidos na pesquisa.

O período da pesquisa se estendeu por aproximadamente dois bimestres letivos, nos quais se discutiram assuntos delimitados e inerentes aos conteúdos da disciplina História correspondente ao $3^{\circ}$ ano, abordando primeiramente temas relacionados à Primeira Guerra Mundial, ao período entre guerras, a regimes totalitários e à Segunda Guerra Mundial. Posteriormente trabalhou-se a "Era Vargas", o "Período democrático de 1945 a 1964" e a "Ditadura civil-militar". Todos esses temas tiveram ampla discussão e interações fomentadas pelas diversas postagens de material de estudos dos mais variados formatos digitais disponíveis na internet.

Em cada grupo foram criados fóruns de discussão, centrais para tirar dúvidas, desenvolver textos colaborativos e compartilhar links, vídeos, sites, imagens e áudios que pudessem auxiliar e estimular o aprendizado histórico.

A partir da formação dos grupos descritos no Quadro 2, fizeram-se as observações e as intervenções que nortearam a pesquisa, subsidiando o encontro de dados e situações que puderam ser apreciados qualitativamente no produto final e na conclusão da pesquisa.

A pesquisa, por sua natureza, foi aplicada com a abordagem exploratória descritiva do problema, utilizando procedimentos técnicos embasados no método da pesquisa-ação, ao passo que o pesquisador teve participação de cunho colaborativo na pesquisa, promovendo intervenções que constituíram a criação de grupos na plataforma do aplicativo WhatsApp na turma envolvida na investigação. Pesquisa-ação, segundo a definição de Thiollent (2011, p.20), é "um tipo de pesquisa social com base empírica, concebida e realizada em estreita associação com uma ação ou com a resolução de um problema coletivo, em 
que os pesquisadores e os participantes representativos da situação ou do problema estão envolvidos de modo cooperativo ou participativo".

A atuação dos alunos e professores no ambiente virtual do WhatsApp foi objeto de análise e avaliação, servindo de parâmetro para se saber se houve mudanças de comportamento, aquisição de competências que possibilitem a evolução ou não no aprendizado e no ensino da disciplina História.

\section{ANÁLISE DOS DADOS E INFORMAÇÕES OBTIDOS}

A análise dos dados se deu por meio da apreciação dos grupos formados no WhatsApp, levando-se em consideração se de fato houve melhoria ou não e aumento no nível de participação nas aulas presenciais, mudanças de atitude e de comprometimento nos estudos, mudanças na relação professor-aluno e aumento no desempenho escolar de um bimestre para outro, tomando-se como parâmetro de comparação o bimestre anterior à realização da pesquisa. Posteriormente, verificou-se se os grupos do WhatsApp, quando utilizados com intencionalidade pedagógica, podem promover a aprendizagem colaborativa por meio da mobilidade e da ubiquidade, podendo ou não esses grupos servirem de extensão da sala de aula no ensino de História.

O último grupo a ser formado, o de avaliação, teve papel crucial na análise dos demais e na síntese das discussões e constatações dos resultados obtidos, informações expressas no Quadro 3.

Quadro 3 - Síntese das discussões do Grupo de Avaliação

\begin{tabular}{|c|c|c|c|}
\hline Participante & Pontos negativos & Pontos positivos & Sugestões \\
\hline $\begin{array}{l}\text { Alunos menos } \\
\text { participativos }\end{array}$ & $\begin{array}{l}\text { - Aumentou a quantidade } \\
\text { de exercícios e } \\
\text { atividades; } \\
\text { - Não tinha crédito para } \\
\text { acessar a internet; } \\
\text { - Não dava para } \\
\text { acompanhar todas as } \\
\text { postagens; } \\
\text { - Meu celular não } \\
\text { conseguia ter acesso a } \\
\text { todos os vídeos. }\end{array}$ & $\begin{array}{l}\text { - Melhorou a relação } \\
\text { professor-aluno; } \\
\text { - Facilitou os estudos; } \\
\text { - Deixou as aulas menos } \\
\text { chatas; } \\
\text { - Tivemos mais tempo para } \\
\text { estudar; } \\
\text { - Ajudou a tirar dúvidas. }\end{array}$ & $\begin{array}{l}\text { - A escola deveria } \\
\text { liberar o sinal de } \\
\text { wi-fi para os } \\
\text { alunos; } \\
\text { - Cada professor } \\
\text { deveria criar um } \\
\text { grupo para sua } \\
\text { disciplina. }\end{array}$ \\
\hline
\end{tabular}


continuação

\begin{tabular}{|c|c|c|c|}
\hline $\begin{array}{l}\text { Alunos mais } \\
\text { participativos }\end{array}$ & $\begin{array}{l}\text { - Aconteceram muitas } \\
\text { conversas paralelas nos } \\
\text { grupos, mesmo que } \\
\text { cada grupo tivesse sua } \\
\text { função específica; } \\
\text { - Alguns colegas queriam } \\
\text { esclarecimentos de } \\
\text { forma imediata, mesmo } \\
\text { sabendo que o prazo } \\
\text { para as respostas era até } \\
\text { o fim do dia seguinte; } \\
\text { - Houve muita pergunta } \\
\text { repetida, pois tinha } \\
\text { gente que não lia o } \\
\text { histórico do grupo e } \\
\text { acabava perguntando a } \\
\text { mesma coisa que outros } \\
\text { colegas. }\end{array}$ & $\begin{array}{l}\text { - Pude estudar mais e até } \\
\text { ajudar meus colegas; } \\
\text { - Facilitou os estudos de temas } \\
\text { históricos que eu não } \\
\text { entendia muito só com as } \\
\text { explicações do professor na } \\
\text { sala; } \\
\text { - Ajudou a tirarmos dúvidas } \\
\text { sem ter que esperar uma } \\
\text { semana até a próxima aula; } \\
\text { - Aumentou a comunicação } \\
\text { com o professor; } \\
\text { - Todos os alunos sabem usar } \\
\text { o aplicativo; } \\
\text { - Dá para estudar em qualquer } \\
\text { lugar e ter o professor por } \\
\text { perto. }\end{array}$ & $\begin{array}{l}\text { - Os alunos com } \\
\text { mais conheci- } \\
\text { mento poderiam } \\
\text { ajudar mais os } \\
\text { colegas menos } \\
\text { preparados em } \\
\text { outras discipli- } \\
\text { nas através de } \\
\text { grupos criados } \\
\text { para esse fim, } \\
\text { seria uma espé- } \\
\text { cie de grupo de } \\
\text { reforço. }\end{array}$ \\
\hline $\begin{array}{l}\text { Professor } \\
\text { da turma }\end{array}$ & $\begin{array}{l}\text { - Mesmo com horários } \\
\text { estipulados para as } \\
\text { perguntas, alguns } \\
\text { alunos postavam suas } \\
\text { dúvidas tarde da noite; } \\
\text { - Por não estar habituado } \\
\text { a usar esse aplicativo } \\
\text { como ferramenta de } \\
\text { ensino, me vi } \\
\text { sobrecarregado em } \\
\text { alguns momentos por } \\
\text { não poder atender } \\
\text { todas as postagens a } \\
\text { mim direcionadas. }\end{array}$ & $\begin{array}{l}\text { - Experiência inovadora e } \\
\text { estimulante entre professores } \\
\text { e alunos; } \\
\text { - Pude conhecer melhor meus } \\
\text { alunos, estreitando laços de } \\
\text { confiança; } \\
\text { - Proporcionou aprendizagem } \\
\text { coletiva, colaborativa e trocas } \\
\text { constantes de conhecimento; } \\
\text { - As discussões iniciadas na } \\
\text { sala de aula eram ampliadas } \\
\text { nos grupos e voltavam para a } \\
\text { sala com teor mais crítico; } \\
\text { - Houve aumento nas notas do } \\
4^{\circ} \text { bimestre em relação ao } 3^{\circ} \\
\text { bimestre, período } \\
\text { correspondente à atuação } \\
\text { nos grupos; } \\
\text { - Foi perceptível um aumento } \\
\text { da participação dos alunos } \\
\text { nas aulas presenciais, até os } \\
\text { menos participativos } \\
\text { passaram a interagir nas } \\
\text { aulas; } \\
\text { - Possibilitou adiantar } \\
\text { conteúdos e assuntos. }\end{array}$ & $\begin{array}{l}\text { - Utilizar a parti- } \\
\text { cipação nos gru- } \\
\text { pos como ele- } \\
\text { mento na } \\
\text { composição da } \\
\text { nota, desde que } \\
\text { todos os alunos } \\
\text { possam efetiva- } \\
\text { mente participar } \\
\text { dos grupos. }\end{array}$ \\
\hline
\end{tabular}

Fonte: resultados da pesquisa. 
As conclusões das discussões indicaram que os grupos do WhatsApp podem efetivamente ser utilizados como extensões da sala de aula, desde que sigam um planejamento de cunho pedagógico que possibilite, de forma eficaz, a promoção de aprendizagem colaborativa, móvel e ubíqua defendida nesta pesquisa.

\section{O ENSINO DE História E O WhatsApp}

O ensino de História vem passando por várias transformações no decorrer das últimas décadas, e a concepção de Educação Histórica vem se firmando como base para o desenvolvimento do pensamento histórico e a formação da consciência histórica do público escolar da educação básica (Schmidt; Barca, 2009). Nesse sentido e nessa concepção de ensino de História, o trabalho com a diversidade de fontes históricas contidas no universo da grande rede vislumbra a possibilidade de os alunos reunirem condições de ler, interpretar fontes, conhecer pontos de vista que os levem a pensar historicamente com a intermediação e orientação do professor (Barca, 2007).

Para que de fato o ensino de História conflua para essa educação histórica, as aulas devem convergir para verdadeiras pesquisas históricas, que na definição de Rüsen (2007, p.104) são

Um processo cognitivo, no qual os dados das fontes são apreendidos e elaborados para concretizar ou modificar empiricamente perspectivas (teorias) referentes ao passado humano. A pesquisa se ocupa principalmente da realidade das experiências, nas quais o passado se manifesta perceptivelmente, ou seja: de "fontes" ... A pesquisa é, por conseguinte, o processo no qual se obtém, dos dados das fontes, o conhecimento histórico controlável.

A internet, com sua infindável diversidade de tipos de fontes associada a sua velocidade peculiar em obter acesso e compartilhamento dessas fontes em formatos digitais, facilita aos alunos, e consequentemente aos professores, a realização de pesquisas e estudos de forma mais efetiva, cabendo aos docentes o cuidado na seleção e uso de tais fontes no meio virtual, pois "A rede está repleta de sites com informações históricas questionáveis, blogs que perpetuam memórias, distorcem informações" (Ferreira; Franco, 2013, p.166). É 
necessário rigor e preparo para poder, de fato, fazer uma análise crítica e reflexiva das fontes e, com isso, reler esses vestígios digitais e reinterpretá-los à luz do conhecimento histórico (Ferreira; Franco, 2013).

Ensinar História e construir o saber histórico com o auxílio de ferramentas digitais amplia de forma exponencial o acesso às fontes históricas, por conseguinte, possibilita aos professores enriquecer o processo de ensino-aprendizagem com a incorporação de novas fontes e saberes (Fonseca, 2009).

Interagir, colaborar, ressignificar e compartilhar são ações constantes e incessantes dentro do universo das redes sociais on-line, características essas que podem estimular a criticidade dos alunos que porventura disponham de acesso e orientação que os instiguem a desenvolver tais objetivos. O mediador desse processo pode e deve ser o professor, e a tarefa pode caber ao professor de História, pois:

O ensino via redes pode ser uma ação dinâmica e motivadora. Mesclam-se nas redes informáticas - na própria situação de produção e aquisição de conhecimentos - autores e leitores, professores e alunos. As possibilidades comunicativas e a facilidade de acesso às informações favorecem a formação de equipes interdisciplinares de professores e alunos, orientadas para a elaboração de projetos que visem à superação de desafios ao conhecimento; equipes preocupadas com a articulação do ensino com a realidade em que os alunos se encontram, procurando a melhor compreensão dos problemas e das situações encontradas nos ambientes em que vivem ou no contexto social geral da época em que vivemos. (Kenski, 2003, p.74)

O saber histórico pode ser construído de forma sólida e devidamente adequada, tanto dentro da sala de aula formal como fora dela, em ambientes virtuais mediados pelas TDIC. O que vai garantir o sucesso do ensino e da aprendizagem será a postura do professor diante dessas possibilidades, pois o saber histórico pode ser construído ou negligenciado em ambas as situações.

A Figura 1, a seguir, ilustra como ocorre o processo de construção do saber histórico dentro dos grupos formados na plataforma do aplicativo WhatsApp. 
Figura 1 - Construção do conhecimento histórico a partir do uso pedagógico dos grupos do WhatsApp

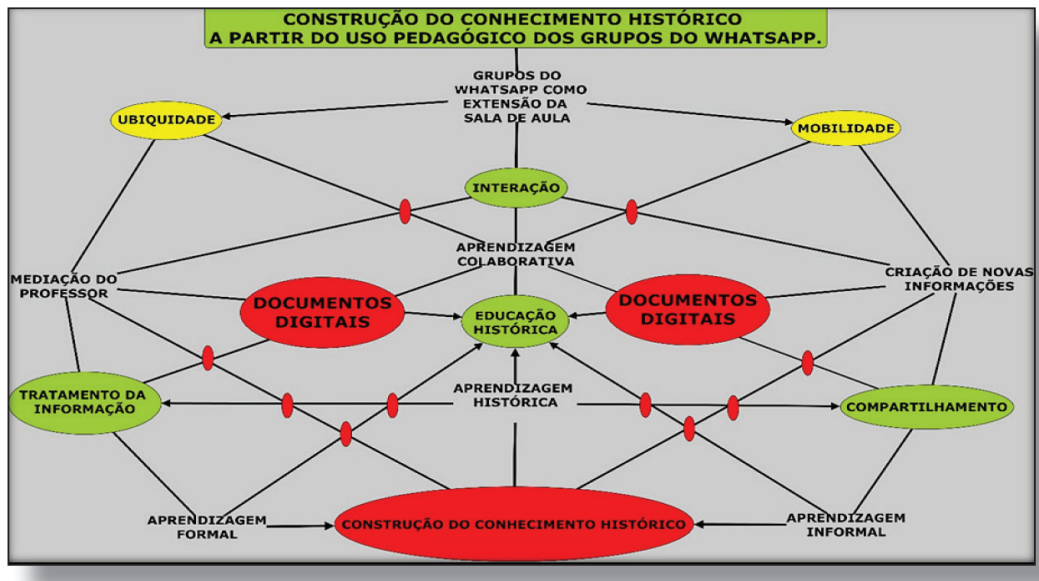

Fonte: Figura estruturada pelo autor.

A construção do conhecimento histórico dentro do ambiente virtual dos grupos do WhatsApp se materializa como extensão da sala de aula, ao passo que conteúdos da disciplina de História, que são trabalhados em sala (ambiente formal de aprendizagem), podem ser explorados mais efetivamente por muitas outras formas e meios, na interação contínua entre alunos e professor.

O esquema representado pela Figura 1 perpassa pela ação constante de acesso aos conteúdos, informações e pesquisas dentro do universo da internet/ $w e b$, os quais promovem interação, compartilhamento e reconstrução de sentidos e, consequentemente, construção de conhecimentos que se alimentam e refazem a partir da mobilidade, ubiquidade e cooperação, decorrentes do uso pedagógico do aplicativo. Criam-se assim possibilidades de coautoria e coprodução de conhecimento em múltiplas perspectivas, elementos marcantes da aprendizagem colaborativa.

Destaca-se ainda que o trato com documentos digitais e as diferentes linguagens que se manifestam e convergem em formato digital na rede provocam um aumento exponencial na quantidade de fontes/informações que irão subsidiar a aprendizagem histórica, intermediada e construída de forma colaborativa dentro e fora da sala de aula, nos grupos do WhatsApp. 
Nos grupos inseridos no ambiente digital, mediados pelo professor, os alunos conseguem suprir suas "carências de orientação que se articulam na forma de interesse cognitivo pelo passado" (Rüsen, 2001, p.30), considerado aqui como interesse em buscar entender os acontecimentos e conteúdos históricos, procurando sentido, reconstruindo o saber histórico de forma colaborativa e de certa forma transformadora, com auxílio e uso de maneira pedagógica das TDIC no ensino da disciplina História.

\section{CONSIDERAÇÕES FINAIS}

Considerando o número de usuários do WhatsApp no Brasil e no mundo, podemos afirmar que esse aplicativo ainda está sendo pouquíssimo explorado no contexto educacional, dada a sua rica variedade de possibilidades de usos pedagógicos, já mencionada no decorrer deste trabalho.

Nossa investigação, realizada em uma escola do sudeste paraense, proporcionou resultados interessantes, levando-nos a constatar algumas possibilidades reais de uso dos grupos do WhatsApp, considerados aqui como redes sociais on-line, no sentido de torná-las ferramentas aliadas da ação docente, quando esses grupos são utilizados com intencionalidade pedagógica e se transformam de fato em extensão da sala de aula.

No ensino de História essas potencialidades foram constatadas na medida em que o aprendizado histórico foi facilitado com a ampla participação dos alunos e do professor da turma, os quais empreenderam um volume muito alto de interações, compartilhamento de informações de cunho histórico, com tratamento crítico e reflexivo das fontes digitais utilizadas nas discussões e estudos realizados nos grupos e nas aulas presenciais.

A sensação de ubiquidade, no que tange à versatilidade e à rapidez com que as respostas e orientações eram postadas para sanar dúvidas e questionamentos, associada ao fato de se poder estudar e aprender os assuntos e conteúdos da disciplina História em qualquer hora e lugar, levou os sujeitos da pesquisa a desenvolverem um aprendizado histórico construído de forma coletiva e colaborativa.

A popularidade do WhatsApp foi um fator favorável na aplicação da investigação. Os alunos se sentiram à vontade para utilizar o aplicativo com fins pedagógicos e de forma planejada mediante a supervisão e orientação do 
professor e do pesquisador, uma vez que o método da pesquisa-ação requer não apenas a participação do pesquisador, mas também sua intervenção direta no decorrer da pesquisa.

A grande maioria dos alunos, como também o professor da turma, afirmaram que a participação nos grupos do WhatsApp facilitou a promoção do ensino e da aprendizagem dos conhecimentos históricos.

Outro fato interessante, é que no decorrer da pesquisa-ação, professores de outras disciplinas passaram a adotar a criação de grupos com finalidade pedagógica em diferentes turmas, e até mesmo a direção da escola passou a usar alguns desses grupos para se aproximar dos alunos e utilizar esse espaço para expor avisos e se comunicar com os membros dos grupos. Nessa perspectiva, está sendo avaliada a possibilidade de criar grupos com os pais dos alunos, na tentativa de trazê-los, mesmo que de forma virtual, para mais perto da comunidade escolar. Tudo isso, de certa forma, são transformações oriundas das intervenções e dos esforços da realização da pesquisa.

Mas nem tudo são flores. Muitas foram as dificuldades para iniciar, dar corpo e concluir a pesquisa. A escassez de tempo para efetuar as leituras necessárias para o embasamento teórico e metodológico da pesquisa surgiram do fato de não ter conseguido licença aprimoramento (afastamento) nas instituições com as quais o pesquisador tem vínculo efetivo, de modo que o acúmulo de tarefas laborais da atividade docente, somado à carga nada leve das atividades acadêmicas, tornasse árdua a caminhada rumo à conclusão deste trabalho.

Outro aspecto externo, a greve dos professores da rede estadual do Pará, retardou o início da pesquisa, previsto para o começo do $2^{\circ}$ semestre de 2015. Em relação aos temas/conteúdos trabalhados com os alunos, não se verificaram limitações quanto à aplicabilidade por meio digital.

Na pesquisa em si, apontaram-se as limitações e dificuldades que de certa forma podem comprometer o objetivo de transformar o aplicativo em parte extensiva e complementar da sala de aula. Problemas de ordem financeira e técnica podem excluir alunos que não dispõem de smartphones, planos de internet em seus celulares ou mesmo internet em suas residências, dificultando o uso e principalmente o acesso dos alunos às ferramentas e aos recursos digitais disponíveis. 
Outro fator a se destacar foi o estreitamento de laços que promoveu uma melhora considerável na relação professor-aluno, pois, segundo os próprios envolvidos na pesquisa, o respeito e a consideração entre alunos e professor aumentaram na medida em que passaram a se conhecer melhor por meio dos grupos do WhatsApp. Diminuiu a distância entre eles, proporcionando aulas "menos chatas", além do fato de os alunos sentirem o professor muito mais presente e atuante dentro e fora da sala de aula.

A criação conjunta das regras de participação nos grupos foi ponto chave para que pudessem funcionar com finalidade pedagógica, pois seria muito difícil manter a ordem e o foco, e consequentemente atingir os objetivos da pesquisa, caso a maioria dos alunos descumprisse tais regras.

Positivamente, cada vez que essas regras eram quebradas, os próprios alunos reprimiam o transgressor, alertando para a finalidade dos grupos e lembrando que era preciso cumprir as normas estabelecidas coletivamente. Essa postura de disciplina e cooperação acabava refletida em sala de aula, quando o professor passou a notar mudanças de atitudes que se materializaram na diminuição dos casos de indisciplina durante as aulas de História.

Podemos afirmar, portanto, que foram alcançados todos os objetivos propostos em nosso trabalho, possibilitando concluir que, de fato, os grupos do aplicativo WhatsApp podem efetivamente ser utilizados de forma pedagógica a ponto de servirem como extensão da sala de aula na disciplina História.

Finalizamos certos de não termos esgotado as discussões acerca do uso, com intencionalidade pedagógica, das TDIC no ensino de História; tampouco demos conta de explorar todas as possibilidades didáticas do aplicativo WhatsApp e das redes sociais on-line formadas por seus grupos. No entanto, estamos cientes de que esta pesquisa, mesmo que de forma incipiente, contribui no sentido de proporcionar aos profissionais da História formação e competências para a utilização dessas ferramentas no ensino e na aprendizagem histórica.

\section{REFERÊNCIAS}

BARCA, Isabel. A educação histórica numa sociedade aberta. Currículo sem Fronteiras, v.7, n.1, p.5-9, 2007.

DEMO, Pedro. Habilidades do século XXI. Boletim Técnico do Senac, Rio de Janeiro, 
v.34, n.2, maio/ago. 2008. Disponível em: http://www.senac.br/bts/342/artigo-1. pdf; Acesso em: 12 fev. 2016.

FERREIRA, Marieta de M.; FRANCO, Renato. Aprendendo História: reflexão e ensino. Rio de Janeiro: Ed. FGV, 2013.

FLEURY, Newton M. Sistemas de informações gerenciais. Universidade Federal Fluminense. Niterói, 2003. (Mimeo).

FONSECA, Selva G. Fazer e ensinar História. Belo Horizonte: Dimensão, 2009.

GOMEZ, Margarita V. Cibercultura, formação e atuação docente em rede: guia para professores. Brasília: Liberlivros, 2010.

KENSKI, Vani M. Tecnologias e ensino presencial e a distância. Campinas: Papirus, 2003. (Série Práticas Pedagógicas).

LÉVY, Pierre. Cibercultura. Trad. Carlos Irineu da Costa. São Paulo: Ed. 34, 1999.

LOPES, Cristiano G. Aprendizagem colaborativa e o ensino de História na palma da mão: o WhatsApp como ferramenta de ensino aprendizagem. (Mestrado profissional em Ensino de História) - Universidade Federal do Tocantins. Araguaína, 2016.

LORENZO, Eder M. A utilização das redes sociais e a Educação: a importância das redes sociais na educação. 3.ed. São Paulo: Clube de Autores, 2013.

MORAN, José M. Educação híbrida: um conceito chave para a educação, hoje. In: BACICH, Lilian; TANZI NETO, Adolfo; TREVISANI, Fernando de M. (Org.) Ensino híbrido: personalização e tecnologia na educação. Porto Alegre: Penso, 2015. p.27-45.

RECUERO, Raquel. Redes sociais na internet. Porto Alegre: Sulina, 2009.

RÜSEN, Jörn. Razão histórica: Teoria da História: os fundamentos da ciência histórica. Trad. Estevão de Rezende Martins. Brasília: Ed. UnB, 2001.

Reconstrução do passado: Teoria da História II: os princípios da pesquisa histórica. Trad. Estevão de Rezende Martins. Brasília: Ed. UnB, 2007.

SACCOL, Amarolinda; SCHLEMMER, Eliane; BARBOSA, Jorge. M-Learning e U-Learning: novas perspectivas de aprendizagem móvel e ubíqua. São Paulo: Pearson Prentice Hall, 2011.

SCHMIDT, Maria A.; BARCA, Isabel. Aprender História: perspectivas da Educação Histórica. Ijuí: Unijuí, 2009.

THIOLLENT, Michel. Metodologia da pesquisa-ação. 18.ed. São Paulo: Cortez, 2011.

WEBER Aline; SANTOS Rosimary dos; SANTOS Edméa. Caiu na rede é peixe: o currículo no contexto das redes sociais. Conhecimento \& Diversidade, Niterói, n.8, 
p.56-75, jul./dez. 2012. Disponível em: http://www.revistas.unilasalle.edu.br/index.php/conhecimento_diversidade/article/view/972; Acesso em: 20 jun. 2014.

\section{NOTA}

${ }^{1}$ Este artigo é uma versão estendida de comunicação apresentada no Simpósio Internacional de Educação a Distância (SIED)/Encontro de Pesquisadores em Educação a Distância (EnPED), realizado em setembro de 2016 na UFSCar (São Carlos, SP). Trabalho desenvolvido com apoio financeiro da Capes.

Recebido em 27 de julho de 2016. Aprovado em 5 de setembro de 2016. 